\title{
SINTER COOLER DESIGN BY PAUL WURTH*
}

\author{
Martin Dirks ${ }^{1}$ \\ Holger Kassebaum ${ }^{2}$ \\ Daniel Kramer ${ }^{3}$ \\ Fabiana Fonseca de Morais ${ }^{4}$ \\ Mathias Hoffmann ${ }^{5}$ \\ Gilles Nouaille-Degorce ${ }^{6}$ \\ Klaus Peter Kinzel ${ }^{7}$
}

\begin{abstract}
Nowadays the sinter cooler often becomes the bottleneck of the sinter production, with outdated equipment leading to low productivity and high operation and maintenance costs. Furthermore valuable energy is simply destroyed in the cooler, which is not compatible anymore with a cost efficient and environmentally friendly sinter production. Paul Wurth has developed and improved two types of coolers, the annular cooler and the shaft cooler which offer flexible solutions to the specific situation of each client. The classic design of the annular cooler was completely revised and is now composed of a rigid ringframe construction as opposed to the traditional design with individual sintering cars, avoiding the typical problems of centering. Additional features of the PW annular cooler are the low air leakage rate and the increased effective cooling surface due to the removal of dead areas. This leads, in addition to the lower weight, to lower operating costs and a smaller space requirement. The shaft cooler stands out with an even smaller space requirement and a lower sinter outlet temperature because of a very long residence time of the sinter inside the shaft. Its development into a pure counter flow cooler aims at maximizing its energy efficiency, as it is designed as a system with a very low demand for cooling air, high air discharge temperatures and highly reduced dust emissions. For both cooler types flexible heat recovery solutions can be offered. These solutions include the supply of hot combustion air to the ignition hood burners and the sinter strand, the production of steam for the clients steam grid or the production of electric energy.
\end{abstract}

Keywords: Sinter cooler; Annular cooler; Shaft cooler; Recirculation; Heat recovery; Energy efficiency; Reduction of dust emissions; Lower $\mathrm{CO}_{2}$ emissions. 


\section{INTRODUCTION}

Why do we focus on sinter coolers?

It is a known fact that the capacities of existing sinter plants have increased steadily, bringing most of the up to 30 years old sinter coolers to their capacity limits. Because of their outdated technology, the old coolers require longer downtimes and have higher dust emissions. In a time where environmental regulations are tightened and the economic pressures are tremendous, the sinter cooler becomes a serious bottleneck in the chain of production of pig iron.

Therefore Paul Wurth improved and redesigned the existing types of coolers, both annular and shaft cooler, and in parallel went on to develop a more energy-efficient and environmentally friendly sinter cooling solution based on the industrial proven shaft cooler technology.

Additionally to the coolers, waste heat recovery systems are proposed, combining the specific possibilities of the different sinter cooler types with the conditions of the site or the requirements of the customers. By means of in - house calculations and computerized simulations, Paul Wurth is designing the cooler systems for an efficient use of the thermal energy of the hot sinter in a waste heat boiler in order to generate steam and / or power whilst taking into account the local conditions and regulatory requirements.

All sinter coolers are tailor made with special consideration of the sinter cooler bed, the effective cooling area and the air inlet velocity. The customer wishes, the site conditions and requirements from the process engineering are included in the design of every cooler.

\section{MATERIAL AND METHODS}

\subsection{Receiving Chute}

The optimized process of the sinter cooling starts with the controlled filling of the cooling bed. A wrong filling with a segregated bulk leads to an uneven cooling air distribution, which in turn leads to an inefficient cooling and increased dust emissions. All types of Paul Wurth sinter coolers are equipped with specially designed receiving chutes to meet the requirements of a steady filling process and a homogeneous particle size distribution inside the cooling area.

Because of the complex particle size distribution of sinter, it is not trivial to fill a cooler correctly.

Therefore Paul Wurth carried out a computerized DEM simulation with the aim of verifying and illustrates the special design of the chute. The results are shown in figure 1.

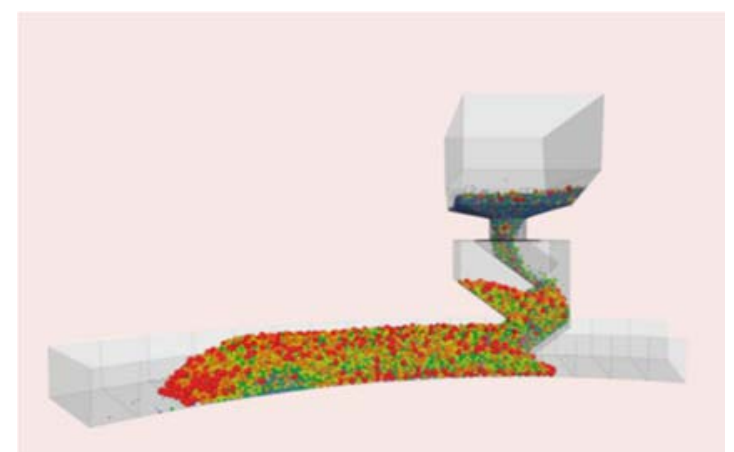

Figure 1: DEM simulation of desegregation chute 
Figure 2 shows an example for a chute designed by using a DEM model.

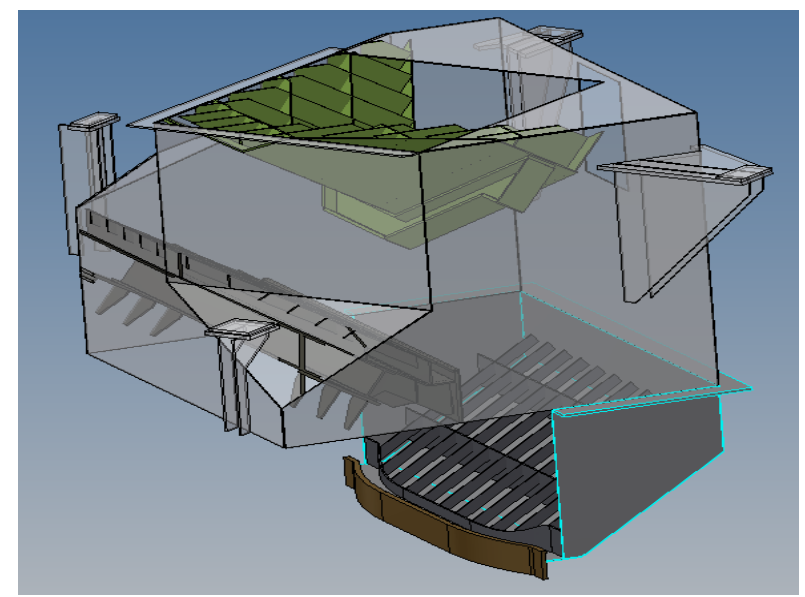

Figure 2: Tailor made desegregation chute

\subsection{Stable Ring Annular Cooler}

The cooler proper is a trough that is charged from the receiving chute above and which discharges the material discontinuously by lowering of the grate bottom.

Contrary to the classic design of the sintercooler which is composed of cooler cars attached one after the other, the Paul Wurth cooler is a rigid trough composed of segments bolted to each other to form a rigid frame. This greatly improves the stability of the cooler and solves the problems of the centering.

Sinter grate bottoms with lamellar air guiding are installed in the segments, which are designed in order to make the least resistance to the cooling air yet to prevent the fines material from passing through.

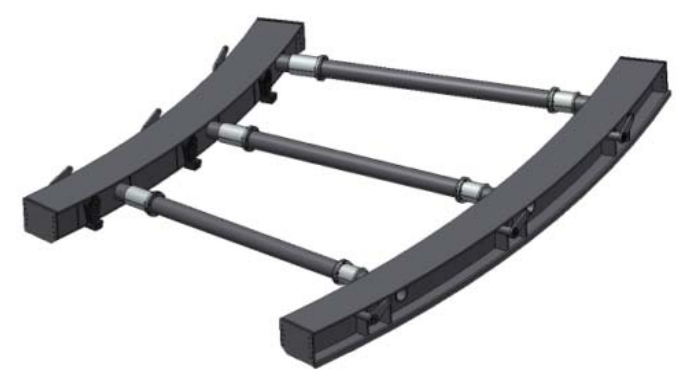

Figure 3: Annular cooler frame

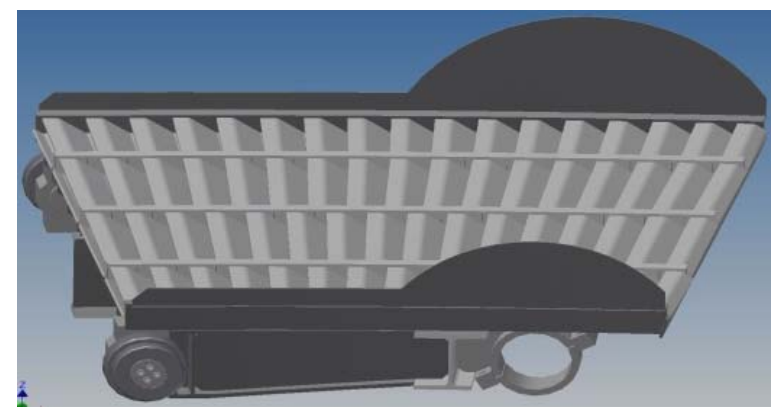

Figure 4: Annular cooler grate bottom

Together with lateral plates and guide tracks the segments form a trough.

An appropriate number of segments are coupled to each other, placed on the carrying wheels and assembled. 


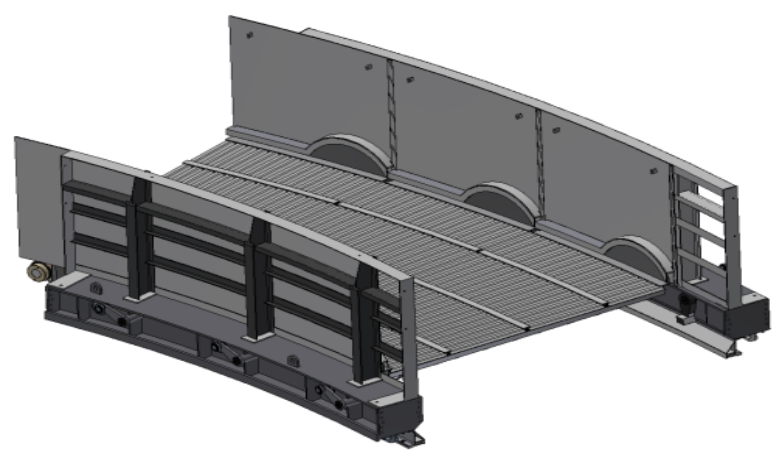

Figure 5: Annular cooler trough segment

The Paul Wurth system does not need any canopy plates. Canopy plates degrade the cooling performance considerably, since they reduce the effective cooling surface. Furthermore, they lead to very high air velocities, which increase the pressure loss and therefore results in a higher required fan power. Single canopy plates and single pellet cars lead to difficulties in sealing. High leakage is expected. This also leads to a large and expensive fan and unnecessarily high operating costs. As a conclusion Paul Wurth's cooler features include the low leakage rate and the increased effective cooling surface due to the removal of dead areas created by the canopy plates. This leads, in addition to the lower weight, to low operating costs and a smaller space requirement. Accordingly, it is possible to increase the efficiency reusing the existing foundations.

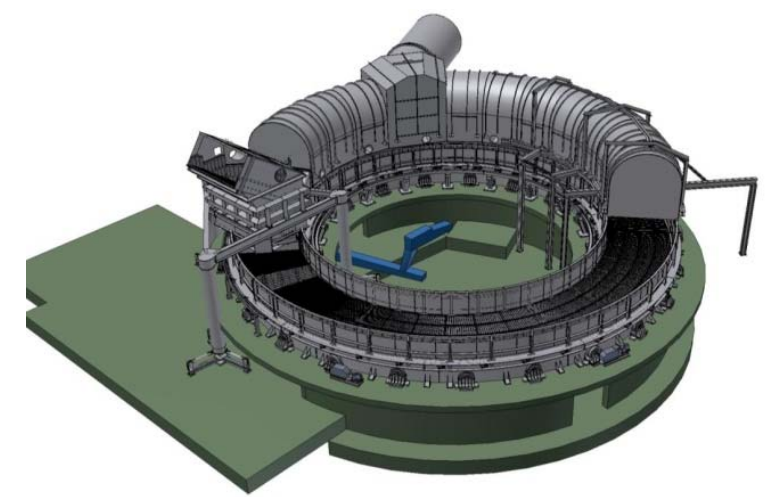

Figure 6: Annular cooler

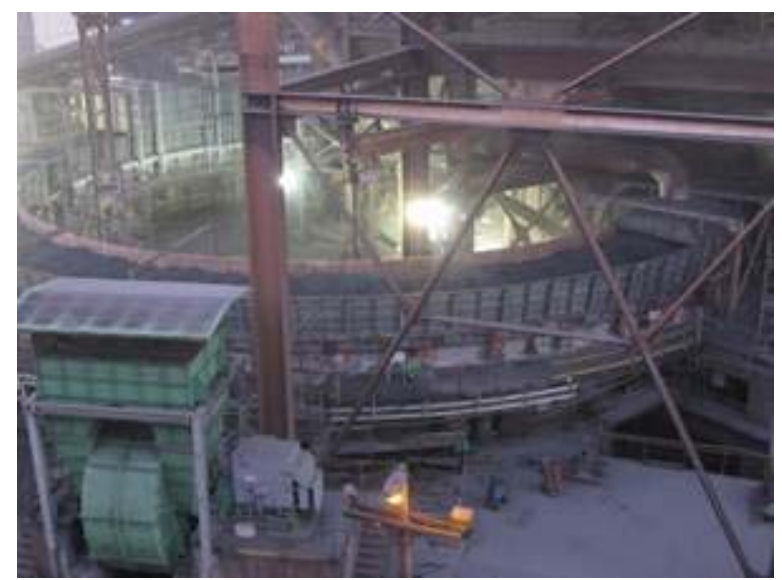

Figure 7: Annular cooler AM Tubarao 


\subsection{Classic Shaft Cooler}

The Shaft cooler technology is an industrially proven technology, which was developped by GHH (now Paul Wurth) and implemented worldwide, e.g. at Nippon Steel Oita, TATA ljmuiden, Hüttenwerke Krupp Mannesmann Duisburg, Thyssen Krupp Steel Duisburg, Salzgitter Flachstahl GmbH Salzgitter, Arcelor Mittal Annaba. Shaft coolers have minor moving parts and fewer parts which are in contact with abrasive sinter than annular coolers.

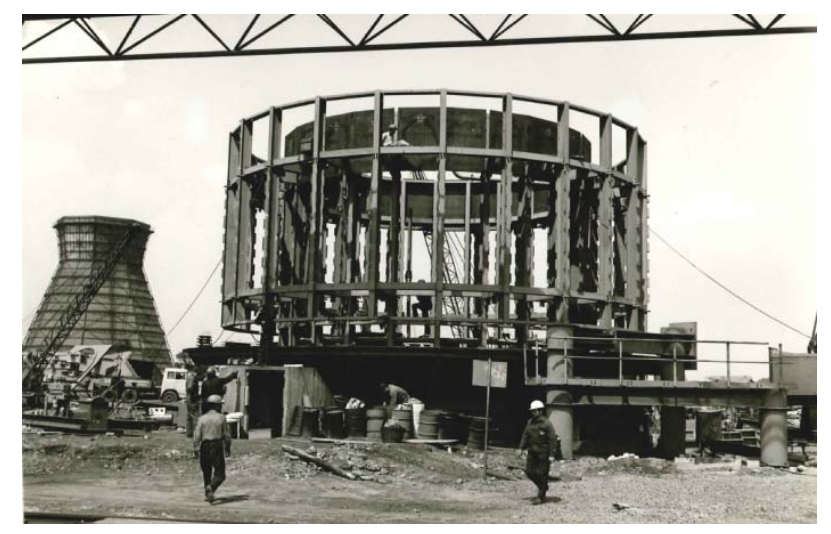

Figure 8: Erection of a shaft cooler at Hüttenwerke Krupp Mannesmann 1971

The shaft cooler is characterised by a long residence of the hot material in the cooling zone, ensuring a low sinter temperature at the outlet.

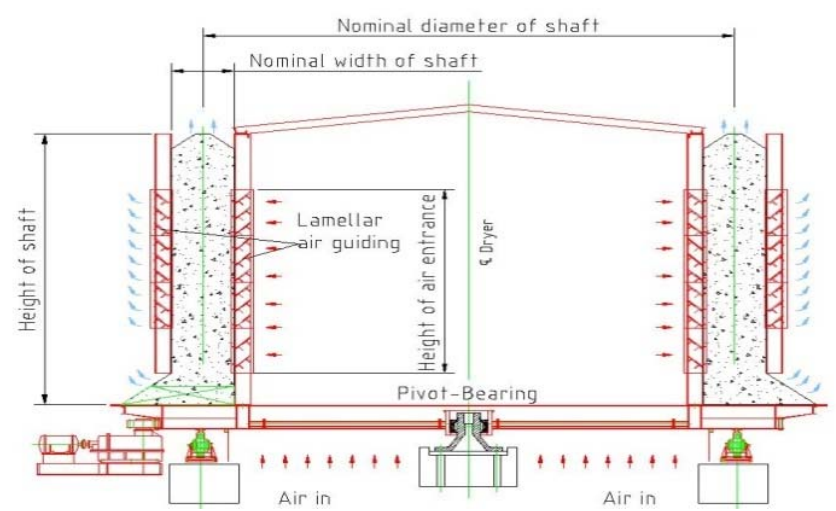

Figure 9: Cylindrical shaft cooler

The cooling air stream is led from below into the cooler inner diameter, and guided by special air guide plates through the bed. The air is escaping the sinter through the outer walls and through the upper surface..

The sinter is charged into the top of the shaft and continuously discharged from the bottom by means of a scraper. The shaft cooler only needs average amounts of cooling air. Due to the high residence time of the sinter in the shaft, low outlet temperatures of the sinter are common. The space requirement in the plant is lower in comparison to all other cooler types.

Figure 10 shows some items of the shaft as an example. Depending on the size of the shaft and space in the plant, segments can be pre-assembled individually. Thus there are very flexible installation concepts in which the crane size and the number of the assembly personnel can be adapted to site conditions. 


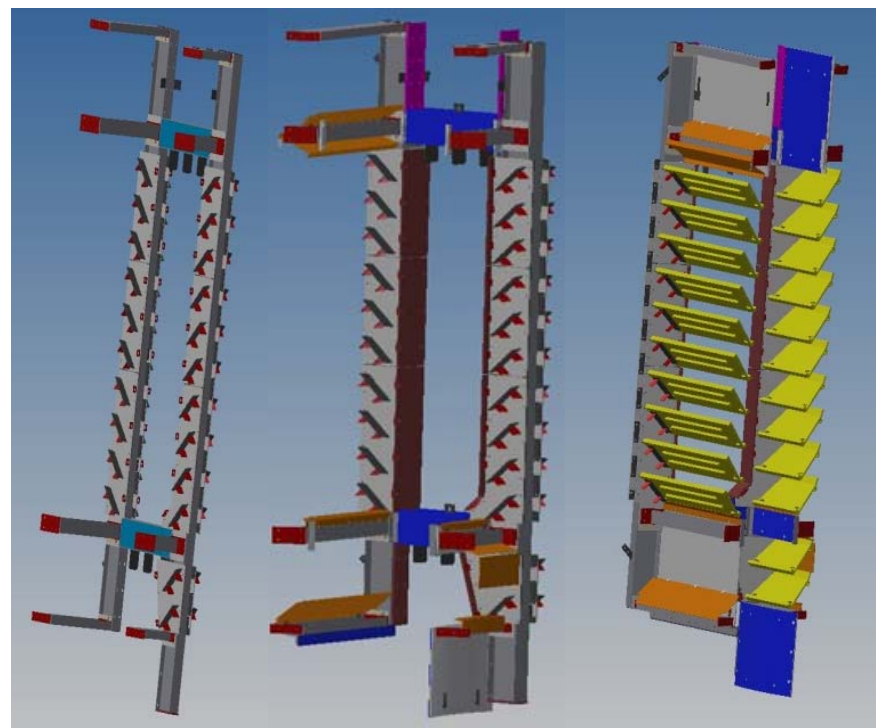

Figure 10: Parts of Cylindrical shaft cooler

The cooler shaft is mounted on a rotating table which is protected with wear plates. The rotation of the cooler is done by electric motors through lantern gears, installed underneath the rotating table. Each motor and gear box are mounted on a common steel frame, so that they can be removed from underneath the cooler easily and maintenance and / or a change of the whole drive can be done quickly. Together with the drive the supporting rail system is installed underneath the rotating table. Carrying wheels arranged on a concrete foundation of the cooler provide the vertical supporting.

One kingpin bearing is located in the centre of the shaft sinter cooler. Its function is to carry the horizontal loads as well as holding the sinter cooler in position (Fig. $11+$ 12).

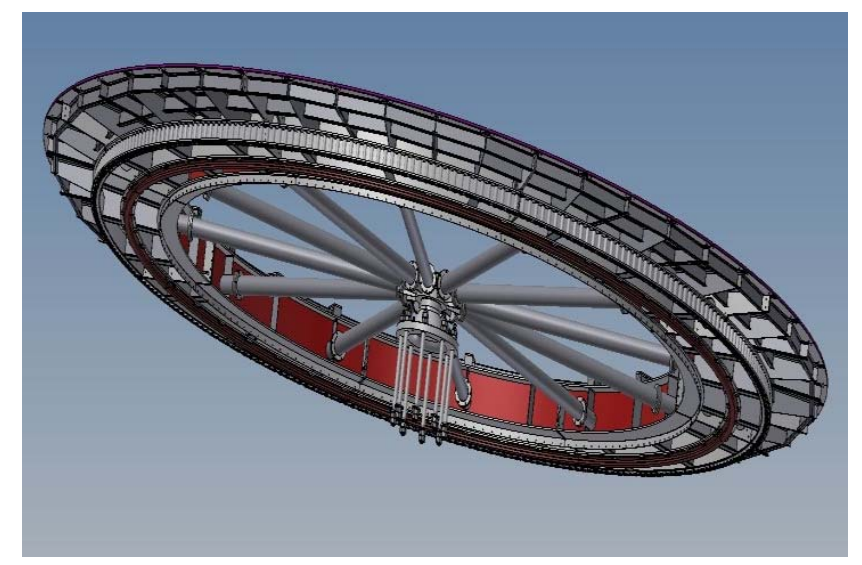

Figure 11: Rotating table with lantern, rails and king pin

The cold sinter is discharged by a tilting discharge beam (Stripper). It is supported in a heavy steel structure and its movement is powered by means of a hydraulic actuated lever system. The discharge of the cold sinter is performed by driving the beam into the lower opening of the cooler shaft. From there, the cold sinter falls into the discharge chute. 


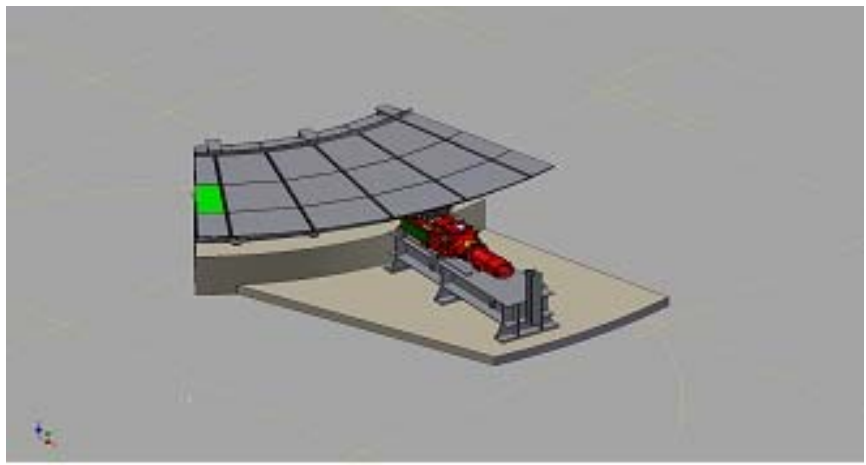

Figure 12: Drive system

\subsection{Counter Flow Shaft Cooler [1]}

Besides cross-current shaft-type coolers, in which the cooling gas mainly flows horizontally (see Fig. 9), counter-current coolers, in which the general motion of the cooling gas is vertically upwards through the sinter, while the sinter moves downwards are also known to be used (see figure 13). These coolers are highly effective because of the thermodynamic advantages of the counter flow regarding the heat transfer between sinter and gas. As a result they are characterised by a very low demand for cooling air, high air discharge temperatures and highly reduced dust emissions.

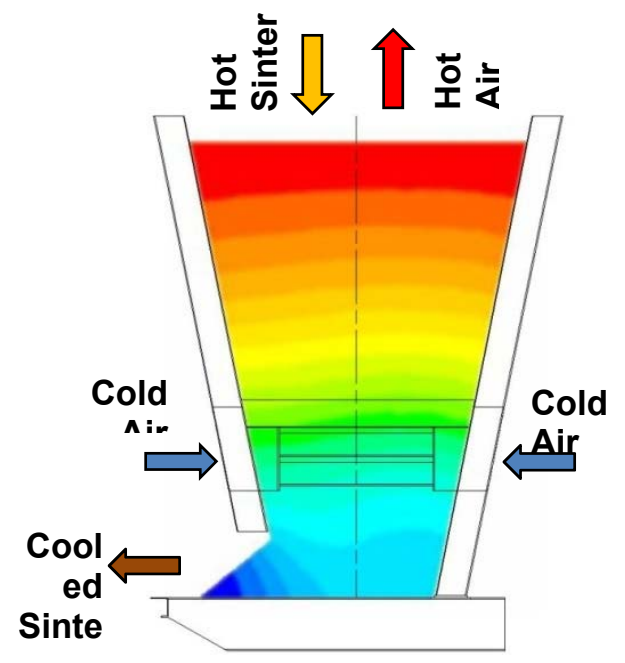

Figure 13: Principle of a counter flow shaft cooler

Based on the industrial proven shaft cooler technology, through the use of modern materials and improvements like maintenance-free bearings, Paul Wurth has further developed this cooler technology.

Similarly to the shaft cooler the counter flow shaft cooler is configured so that during operation the sinter is charged into the charge opening and performs a slow vertical movement towards the discharge opening at the bottom of the cooler. Due to the high sinter residence time in the cooler the sinter will make various complete rotations with the cooler and is thus performs a pseudo helical movement while cooling air is sucked from the outside into the shaft through the radial inlet vanes at the bottom and moves upwards through the sinter shaft [2]. The radial inlet vanes create a tangential airflow into the sinter. Moreover, this airflow can directly act on a radially extending region of the compartment - and the sinter within. While previous 
approaches only considered tangentially arranged inlet vanes, which led to a radially inhomogeneous airflow, the Paul Wurth solution ensures a considerably improved homogeneity of the cooling air distribution. In comparison to a design with additional air ducts in the lower part, the Paul Wurth solution is less complex and abrasion can be minimised.

The discharge of the sinter is done by a Stripper beam almost identical to the beam of a standard shaft cooler.

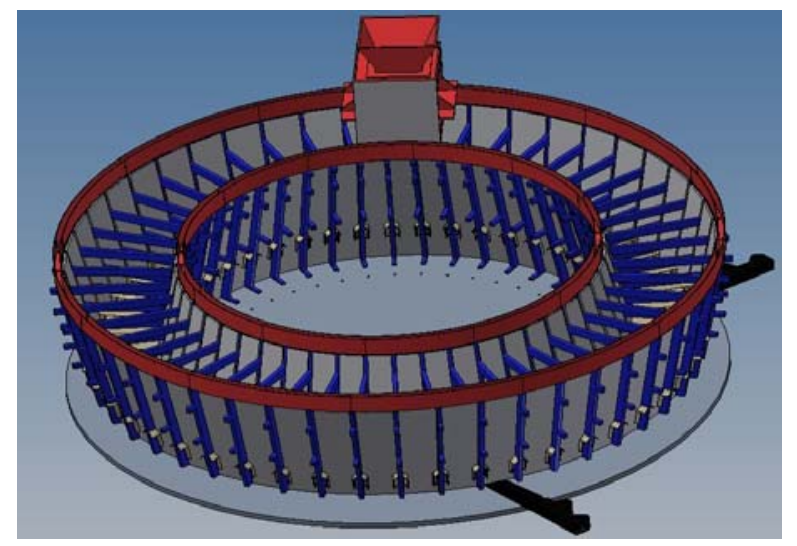

Figure 14: Counter Flow Shaft Cooler

The sinter cooler shaft is designed for the calculated underpressure, sinter load and consists of a steel structure with heavy wear protection. Besides the structural design and appropriate dimensioning of the sinter cooler shaft, the shaft is also calculated to fit the process engineering requirements in a technical optimum. This is done by using CAE programs like commercial fluid dynamic calculations and Paul Wurth inhouse developed software.

The data set will be validated by Paul Wurth's experience to find a customized solution for each application and to suit the customer's requirements and national regulations in terms of emission control.

As an example of the simulation output we show in Fig. 15 the calculated temperature profile in the shaft cooler.
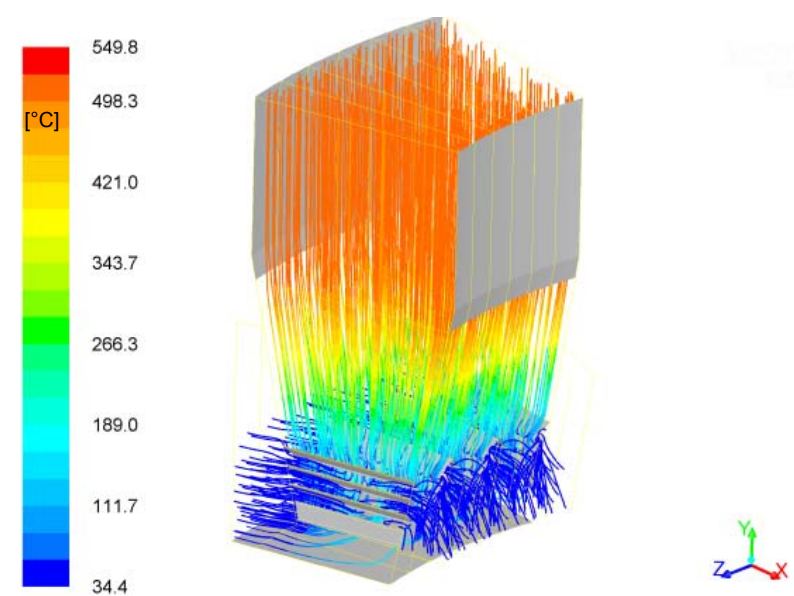

Figure 15: Temperature profile calculation for shaft cooler dimensioning 
Compared with the traditional circular cooler technology, the counter flow shaft cooler technology shows main advantages:

$\checkmark$ Due to the heat transfer in a counter-current flow, the heat recovery rate is $100 \%$. The specific amount of cooling air is approx. $800 \mathrm{~m}^{3} / \mathrm{t}$ sinter, half as much as compared to the usual dimensioning for elder coolers (cp. Fig. 19);

$\checkmark$ Longer residence time of the raw sinter in the cooler which results in a better cooling efficiency. The average discharge temperature at the cooler outlet is generally lower;

$\checkmark$ Smaller footprint for a same productivity;

$\checkmark$ Continuous discharge operations that facilitates the management of the sinter for crushing and screening operations downstream;

$\checkmark$ High reliability and availability due to an uncomplicated system technology;

$\checkmark$ Reduce electricity supply and costs;

$\checkmark$ Significant reduction of operation and maintenance costs;

$\checkmark$ Reduction of dust emissions;

$\checkmark$ Lower greenhouse emissions.

\subsection{Waste Heat Recovery}

For the waste heat recovery, the sintering section and the sintered ore cooling section are the two major sections in a sintering plant. Heat recovery from both parts has been developed, but efficient heat recovery is limited to high gas temperature zones.

The gas temperature distribution is shown in Fig.16 [3]. Even in each section there is a large temperature difference and the average gas temperature in both sections is in the level of $100-150{ }^{\circ} \mathrm{C}$, too low for an effective heat recovery. Only the final part of the sintering section and the primary part of the cooling section, where gas temperature of $300{ }^{\circ} \mathrm{C}$ or higher is thus available [3] are suitable for implementing a waste heat boiler e.g. up to now this statement applies to almost all existing installations. Although the heat recovery zone is limited, the gas volume of the sintering process is sufficient for a practical heat recovery in commercial base.

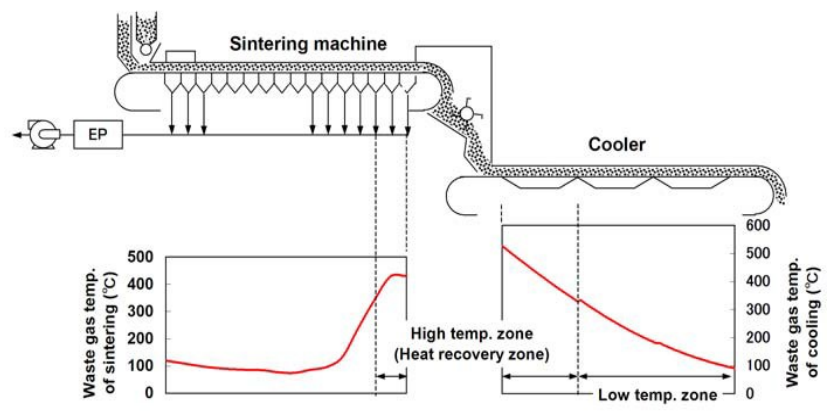

Figure 16: Gas temperature distribution [3]

The above statement is also confirmed by Paul Wurth's measurements and thermodynamic calculations on conventional annular and shaft coolers. 


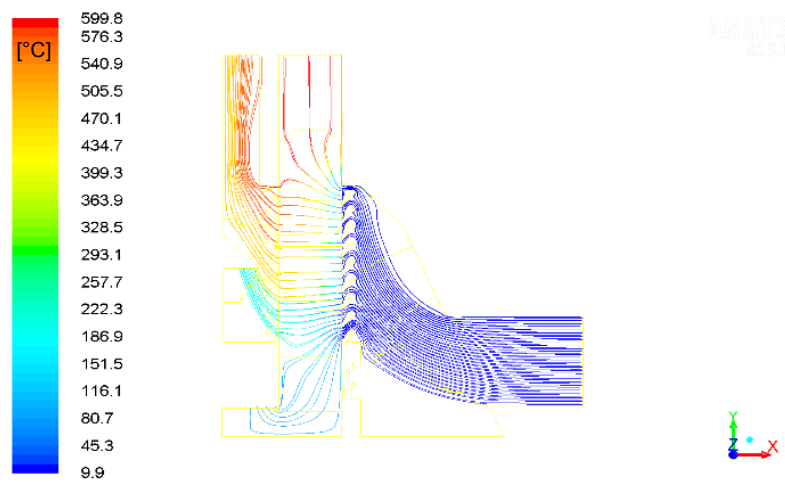

Figure 17: Cooling path temperature shaft cooler

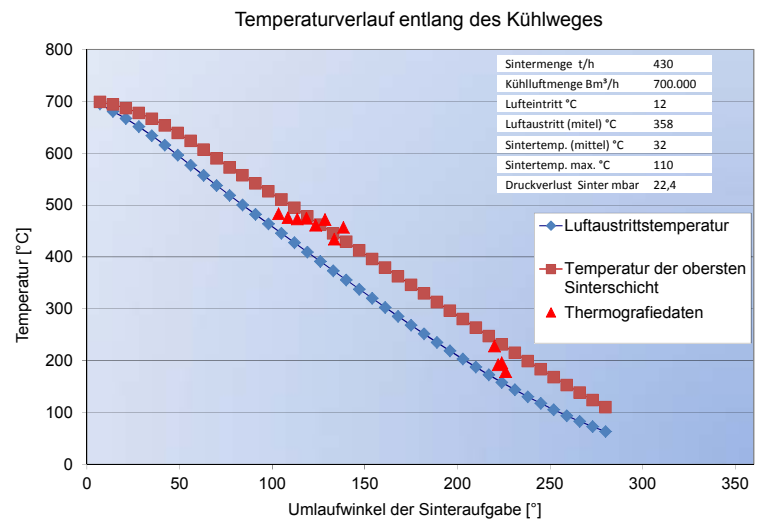

Figure 18: Results cooling path temperature

Depending on the required high temperature level of the off gas, only 30 to $40 \%$ of the cooling air of an annular or linear cooler can be used for heat recovery. A classical annular cooler with an installed cooling fan power of e.g. 5.3 MW, can recover 9.3 MW electrical power by using a steam and turbine process (57t/h steam at $250^{\circ} \mathrm{C}$ and 16 barg).

The situation improves if an exhaust gas recirculation is used. Recirculation increases the heat recovery rate by app. $40 \%$. In this case, four fans have to be installed, which consume $6.8 \mathrm{MW}$ while $13 \mathrm{MW}$ electrical power can be generated $\left(80 \mathrm{t} / \mathrm{h}\right.$ steam at $250^{\circ} \mathrm{C}$ and $\left.16 \mathrm{barg}\right)$ - here we recirculate $100 \%$ hot gas. This, however, corresponds with a significantly increased expenditure on equipment, materials and higher operating costs. The size of this cooler has to be larger, the system is more complicated, inflexible and requires the modification of mechanical components due to higher temperatures.

At the counter flow cooler, $100 \%$ of the cooling air is used for heat recovery and only two streams have to be handled; one to the ignition hood, to preheat combustion air and fuel and the second to the waste heat boiler to produce steam. At the same case as mentioned above, $90 \mathrm{t} / \mathrm{h}$ of steam at $450^{\circ} \mathrm{C}$ and 16 barg can be produced, while adding the possibility of reaching a higher pressure level for the steam, so that the energy output is even higher.

The energy consumption is $3.3 \mathrm{MW}$ for the fans, standing against 14.7 MW electrical power $\left(90 \mathrm{t} / \mathrm{h}\right.$ steam at $450^{\circ} \mathrm{C}$ and $\left.16 \mathrm{barg}\right)$.

Figure 19 illustrates the above named numbers. It is obvious that the counter-current shaft cooler provides the greatest surplus. 


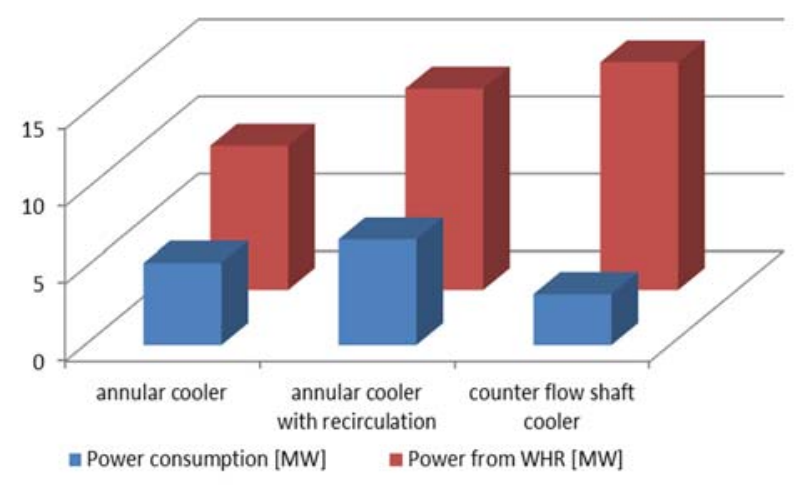

Figure 19: Energy balance

Further impressive are the comparisons on the size and the necessary foundations that lead to the fact that less concrete must be used for the (counter-flow) shaft cooler (approx. factor 12).

Figure 20 shows the size comparison of a conventional annular cooler to one with a hot gas recirculation and to a (counter flow) shaft cooler.

In comparison to an annular cooler respectively annular cooler with recirculation one spares $18.25 \mathrm{~m}$ and $22.25 \mathrm{~m}$ if a shaft cooler is planned.

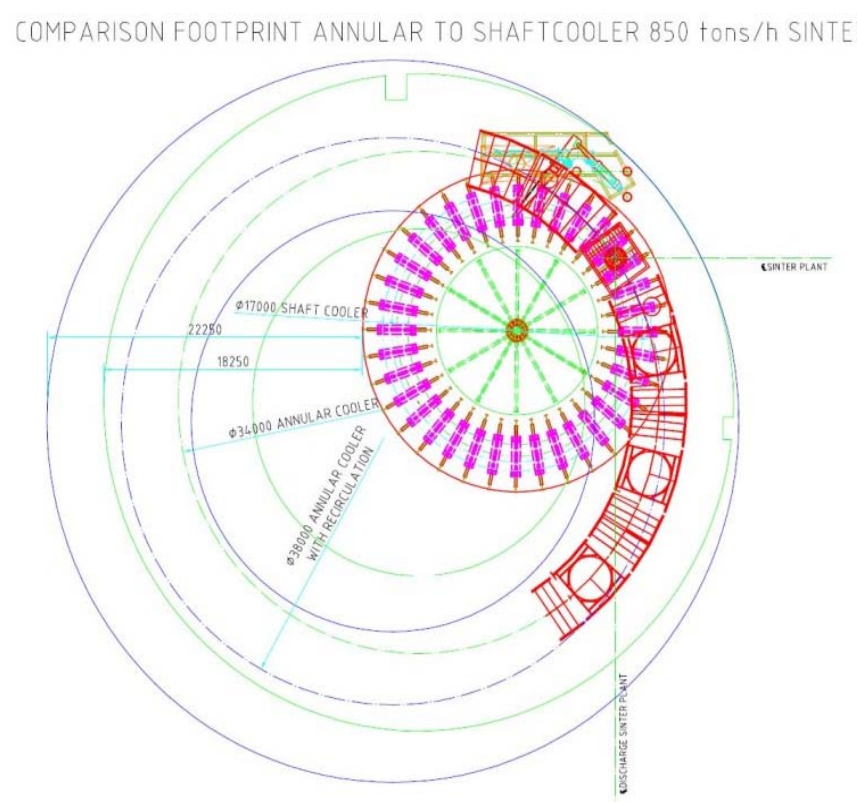

Figure 20: Size comparison

\section{CONCLUSION}

The Paul Wurth annular cooler features have a low leakage rate and an increased effective cooling surface due to the removal of dead areas. In contrast to the traditional design with individual sintering cars, the segments form a stable ring avoiding the typical problems of centering. This leads, in addition to the lower weight, to low operating costs and a smaller space requirement, which allows to increase the efficiency and capacity, while re-using the existing foundations. 
The Shaft cooler technology is characterised by a long residence of the hot material in the shaft, which insures a low sinter temperature at the exit and the additional advantage of a very small footprint so that it is perfectly suited for a replacement of an old cooler in a brown field area with limited available space.

All Paul Wurth sinter coolers are perfectly suited for any type of heat recovery, which can be designed tailor-made to fit each customer's needs. Especially the new Paul Wurth conical shaft cooler is a development of the shaft cooler towards a pure counter flow cooler aiming at maximising the energy efficiency. It is designed as a system with a very low demand for cooling air, high air discharge temperatures and highly reduced dust emissions.

\section{REFERENCES}

1 Greiveldinger, B., Weißert, T., Hosoma, S., Kassebaum, H., et al. Sinter Cooler EP14178804, 2014

2 Cappel \& Wendeborn, Stahleisen, Sintern von Erzen, 1973, Bücher, Band 19, P. 232

3 Maximizing Sintering Plant Heat Recovery, https://steelplantech.com, 2012. 